the intersections of the hour-circles and parallels of declination (at intervals of four minutes in R.A. and $\mathrm{I}^{\circ}$ in declination) in Schönfelds and Gould's Durchmusterung charts, so the plates $(7 \times 5$ in.) in their longest direction have considerable overlap, the linear scale of the negatives corresponding to one degree of arc being 3.8 in. Mr. E. C. Slipher was a co-worker at the telescope, and with the examination of the negatives, but Mr. Lampland is responsible for the magnitudes and determinations of position which accompany the paper in the form of tables. Nearly all the objects dealt with are of magnitude about 12 or fainter.

Radial Velocities of ioo Stars with Measured Parallaxes.-Messrs. W. S. Adams and Arnold Kohlschütter contribute a valuable paper to the May number of the Astrophysical Journal (Contributions from the Mount Wilson Solar Observatory, No. 79) relative to the radial velocity determinations during the past three years of stars fainter than magnitude 5.5 on the visual scale for which observations of parallax are available. The photographs were secured with the 6o-in. reflector in conjunction with the Cassegrain spectrograph adapted for use with one prism, but for stars from 5.5 to 0.5 magnitude a camera lens (Brashear special triplet) of IO2 cm. focal length was used, while for stars fainter than 6.5 a lens (Cooke astrographic type) of $46 \mathrm{~cm}$. focal length was employed. Briefly summarising some of the conclusions derived from this excellent piece of research work, the first to be mentioned is the enormous radial velocities of a few of the stars observed. Thus Lal. I966 and Lal. I5290 indicated velocities of -325 and $-242 \mathrm{~km}$, the first of these being the highest recorded radial velocity among any of the stars. Four other stars exceeded $100 \mathrm{~km}$., and several between 75 and roo $\mathrm{km}$. A notable fact is the great preponderance of large negative over large positive velocities, no less than 75 per cent. of the large velocities observed being negative. The following interesting table shows the stars exceeding radial velocities of $50 \mathrm{~km}$. with their spectral types, showing that nearly all classes of the latter are involved:-

\begin{tabular}{|c|c|c|c|c|c|}
\hline Posi & e (5) & & Negativ & (15) & \\
\hline Groom: 864 & Go & +100 & Ial. 1045 & $\mathrm{~K}_{\mathrm{I}}$ & -58 \\
\hline Groom. I28I & $\mathrm{F}_{9}$ & 84 & Lal. I 966 & $\mathrm{~F}_{3}$ & 319 \\
\hline 20 Leo. Min & GI & 54 & Lal. 4855 & Go & 103 \\
\hline 33 Virginis & $\mathrm{KI}$ & 56 & Lal. $576 \mathrm{I}$ & $\mathrm{A}_{3} p$ & $15 \mathrm{I}$ \\
\hline Lal. 30694 & $\mathrm{G}_{5}$ & +57 & Lal. I 5290 & $\mathrm{~F}_{7}$ & 250 \\
\hline & & & Lal. 21185 & $\mathrm{Ma}$ & 85 \\
\hline & & & Lal. 27744 & G9 & 58 \\
\hline & & & $O \sum 298$ & Ko & 55 \\
\hline & & & W.B. I 5 h 720 & G9 & 54 \\
\hline & & & Lal. 28607 & $\mathrm{~A} 2 p$ & I 58 \\
\hline & & & $72 \omega$ Herculis & Go & 5 \\
\hline & & & 3Ib Aquilæ & G7 & 8 \\
\hline & & & Lal. $37120-1$ & $\mathrm{G}_{2}$ & 143 \\
\hline & & & Lac. $838 \mathrm{I}$ & K6 & 0 \\
\hline & & & $\mathrm{Pi} 23 \mathrm{~h}$ I64 & F8 & \\
\hline
\end{tabular}

It will be noticed that the two stars with the largest proper velocities are of types $\mathrm{F}_{3}$ and $\mathrm{F}_{7}$, and the two succeeding stars are of the A type.

\section{THIRD INTERNATIONAL CONGRESS OF TROPICAL AGRICULTURE.}

THIS congress will be held at the Imperial Institute on June 23-30. Meetings will commence each week-day at I0.30 a.m., except on Saturday, which will be devoted to special visits. The mornings, as a rule, will be devoted to discussions, and the afternoons to papers on special subjects. Only a few of the more important matters to be dealt with can be mentioned here, and those interested should consult the general programme, which can be obtained on application to the general secretaries at the Imperial Institute, South Kensington, S.W.

At the inaugural meeting on June 23 , the president, Prof. Wyndham R. Dunstan, will receive the delegates of the foreign and colonial Governments, and will deliver the presidential address. In the afternoon he will preside at a discussion on "Technical Education in Tropical Agriculture," to which Mr. Dudgeon (Egypt), Dr. Francis Watts (West Indies), Mr. Lyne (Ceylon), Mr. McCall (Nyasaland), and others will contribute.

An interesting feature of the congress will be a series of four special papers to be given on certain afternoons. On Tuesday, June 23, Mr. J. A. Hutton, chairman of the British Cotton Growing Association, will describe the work of that association. The Earl of Derby, president of the association, will take the chair, and Lord Emmott, Under-Secretary of State for the Colonies, will speak. In the same series Sir Louis Dane will preside at a meeting on Thursday afternoon, at which Mr. Shuman will describe the "Utilisation of Sun-power for Irrigation and Other Purposes"; on Friday afternoon Prof. Wallace will lecture on "The Caracul Sheep"; and on Monday afternoon, June 29, Mr. Wigglesworth will describe "The Fibre Industry of British East Africa."

On Wednesday morning, June 24, two discussions will be held; the first, presided over by Sir Ronald Ross, will deal with "Hygiene and Sanitation on Tropical Estates," and the second, at which Sir Sydney Olivier will take the chair, will be concerned with "Legislation against Plant Diseases," to be introduced by a paper from Mr. A. G. L. Rogers, of the Board of Agriculture.

On Thursday morning the president will introduce a discussion on "The Factors which Determine Variation in the properties of Plantation Rubber, with Special Reference to its Uses for Manufacturing Purposes," to which planters, manufacturers, and others will contribute. In the afternoon Sir E. Rosling will preside, and papers on rubber will be read.

On Friday morning the first discussion will be on "Agricultural Credit Banks and Cooperative Societies," at which Sir Horace Plunkett will preside. The second will be on "The Organisation of $\Lambda$ gricultural Departments in Relation to Research," and at this the President will take the chair.

On Monday, June 29, Viscount Kitchener will talse the chair at a discussion on "The Improvement of Cotton Cultivation," at which papers will be read by Mr. Dudgeon (Egypt), Prof. Todd (Nottingham University), Mr. Arno Schmidt (International Federation of Cotton Spinners), and Mr. McCall (Nyasaland). The afternoon will be devoted to sectional meetings for papers on "Cotton" and on "Jute and Hemp Fibres."

Tuesdav, June 30 , will be the last day of the congress. Two sectional meetings for "Cotton" and "Miscellaneous" papers will be held in the morning, and the final meeting of the congress will be held at 3.30 p.m. in the afternoon.

His Majesty the King has graciously consented to become patron of the congress, and His Majesty's Government will give a reception for the delegates and members of the congress at the Imperial Institute on Tuesday, June 23 , at 9.30 p.m. Receptions will also be given by the Royal Colonial Institute (June 24 ) and by the Rubber Growers' Association (June 30 ).

The subscription for membership, including all publications of the congress, is $\mathrm{x} l$. 